\title{
The role of taxanes in triple-negative breast cancer: literature review
}

This article was published in the following Dove Press journal:

Drug Design, Development and Therapy

5 August 2015

Number of times this article has been viewed

\author{
Giorgio Mustacchi' \\ Michelino De Laurentiis ${ }^{2}$ \\ 'Medical Oncology, University \\ of Trieste, Trieste, ${ }^{2}$ Breast Medical \\ Oncology Unit, National Cancer \\ Institute, Fondazione G. Pascale, \\ Napoli, Italy
}

\begin{abstract}
Breast cancer (BC) is the most frequent tumor worldwide. Triple-negative $\mathrm{BCs}$ are characterized by the negative estrogen and progesterone receptors and negative HER2, and represent $15 \%$ of all BCs. In this review, data on the use of taxanes in triple-negative BCs are analyzed, concluding they are effective in any clinical setting (neoadjuvant, adjuvant, and metastatic). Further, the role of nab-paclitaxel (formulation of albumin-bound paclitaxel) in these tumors is also evaluated. The available data show the clinical potential of nab-paclitaxel based combinations in terms of long-duration response, increased survival, and better quality of life of patients with triple-negative metastatic BC. The ongoing trials will give further information on the better management of this type of tumor.
\end{abstract}

Keywords: nab-paclitaxel, paclitaxel, docetaxel, bevacizumab

\section{Introduction}

Breast cancer (BC) is the most frequent tumor worldwide. In 2008, 1,380,000 new cases and 458,000 deaths for BC were reported worldwide, of which there were 332,000 new cases and 89,000 deaths in Europe. Although the improvement in early diagnosis and adjuvant therapy has reduced mortality, $\mathrm{BC}$ is still the main cause of death for cancer in women both in industrialized and in developing countries. ${ }^{1}$

In Italy, BC is the most frequent tumor in women (29\%), with about 48,000 new cases diagnosed in 2014. In 2011, BC represented the first cause of death for cancer in women, with approximately 11,959 deaths estimated. The 5-years relative survival, moderately but constantly increasing apart from other comorbidities, is $87 \%$ for women diagnosed between 2005 and $2007 .^{2}$

$\mathrm{BC}$ is a heterogeneous disease, and therefore, a "golden standard" treatment, suitable for all the molecular types of cancer, is not available. ${ }^{3}$ The most important biological markers, not only for classification of BC but also for, the therapeutic strategy are the hormonal receptors (estrogen [ER] and progesterone $[\mathrm{PgR}]$ receptor) and the HER2 receptor status.

\section{The triple-negative BCs (TNBCs)}

Tumors that are ER-, PgR-, and HER2-negative are known as TNBC and account for about $15 \%$ of BCs. ${ }^{4}$ These tumors develop earlier in life, especially in premenopausal women, and have a poorer prognosis than the other types of $\mathrm{BC}$ due to the higher aggressiveness. These factors may be a major reason for the high-risk relapse, and shorter progression-free survival (PFS) and overall survival (OS) reported for this disease. $^{3-6}$

The main general characteristics of TNBC are summarized in Table 1.
Correspondence: Giorgio Mustacchi Medical Oncology, University of Trieste, Via Lucrezio 9, 34134 Trieste, Italy Tel +393484487005

Fax +39040410237

Email gmustacchi@units.it 
Table I General characteristics of triple-negative BC4,5

- Weak association between tumor size and lymph node involvement

- Quick growth and tissular density similar to normal tissue

- High expression of BRCAI mutation

- High risk of early relapse

- Peak recurrence between the first and third years after diagnosis

- Metastases are rarely preceded by local recurrence

- Higher incidence in younger women, Afro American or Hispanic, and in low socioeconomic conditions

- Stronger association with obesity

- Higher incidence of brain metastases

- Most deaths occur in the first 5 years

- Rapid progression from the onset of metastasis to death

Abbreviation: $\mathrm{BC}$, breast cancer.

TNBC is not a unique clinical entity. It comprises several types of cancers now characterized by molecular profiles, which represent different diseases with probably different treatment options and different response to chemotherapy, biological agents, and/or other therapeutic regimens.

After 2002, gene expression profiles have identified the different molecular subtypes of $\mathrm{BC}$, in particular, in the neoadjuvant setting ${ }^{7-10}$ and in particular, regarding TNBC. ${ }^{11}$ The PAM50 gene expression assay ${ }^{12}$ classifies BCs into at least five groups, including luminal A, luminal B, HER2-enriched, basallike (BL), and normal breast-like. More recent gene expression array analysis has identified six different groups of TNBC, including two BLs (BL1 and BL2), an immune-modulatory (IM), a mesenchymal (M), a mesenchymal stem-like (MSL), and a luminal androgen receptor (LAR) subtype. ${ }^{13}$ Recently Tobin et al reported that with PAM50 intrinsic BC subtypes array, $25 \%$ of relapses were basal, $32 \%$ HER2, $10 \%$ luminal A, 28\% luminal B, and 5\% normal breast-like. Importantly, the intrinsic subtype at relapse was significantly associated with postrelapse survival $(P=0.012) .{ }^{14}$ At the 2015 American Society of Clinical Oncology (ASCO) Meeting, Dent et al presented interesting data from the Surveillance, Epidemiology, and End Results (SEER) database on 10,000 women diagnosed in 2010 and 2011 with TNBC in the USA. ${ }^{15}$ This population reflects the current clinical practice in the USA at the time: $34 \%$ were at stage I, $42 \%$ at stage II, $15 \%$ at stage III, and $6 \%$ at stage IV, with a $24-$ month OS of $97 \%, 93 \%, 71 \%$, and $27 \%$, respectively. The median OS in metastatic disease was 13 months.

\section{The treatment of TNBCs}

A proportion of TNBC is highly sensitive to chemotherapy but with a short PFS and a lower OS. ${ }^{4-6,13,15}$ Current therapeutic strategies include chemotherapeutic drugs (anthracyclines, taxanes, platinum derivatives, and ixabepilone) and biological drugs. ${ }^{5,6}$ The efficacy of anthracyclines and taxanes in metastatic BC is higher in ER-negative tumors; for this reason, both classes are indicated as first-line treatment of TNBC, even if with a short-lasting benefit. ${ }^{4}$ Another group of drugs with proven activity in TNBC are the platinum derivatives cisplatin and carboplatin. ${ }^{3-6}$ The biologic drugs already evaluated or under active research include angiogenesis inhibitors (bevacizumab), PARP1 and EGFR inhibitors, tyrosine kinase and ERK inhibitors, mTOR inhibitors, heat shock protein 90 inhibitors, and AR antagonists..$^{3-6,13}$

\section{Guidelines for the treatment of TNBCs}

There are no specific guidelines for the management of TNBC: the National Comprehensive Cancer Network (NCCN), European Society for Medical Oncology (ESMO), and Associazione Italiana di Oncologia Medica (AIOM) Guidelines recommend that TNBC be treated with chemotherapy (monotherapy or combination therapy) but do not specify the most appropriate drugs (Table 2). ${ }^{1}$

The ESMO Guidelines states that cytotoxic chemotherapy is the standard of care for the treatment of TNBC and that the choice of the regimen should be made after consideration of disease-related factors (disease-free survival [DFS], previous therapies and response, tumor burden, and need for rapid disease/symptom control) and patient-related factors (patient preferences, biological age, menopausal status, comorbidities and performance status, and socioeconomic and psychological factors). Combination chemotherapy is more often required because of frequent visceral involvement, aggressive course, and risk of rapid patient deterioration. Finally, there is no a standard approach for chemotherapy after first line. ${ }^{1}$

\section{The role of taxanes in TNBC}

The role of taxanes in TNBC is well established after the many studies evaluating the efficacy of taxane-based regimens in neoadjuvant, adjuvant, and metastatic disease settings.

\section{The neoadjuvant setting}

Neoadjuvant therapy has been used for a long time for reducing the size and the extension of locally advanced tumors, but now it is extensively used also in early BC not suitable for primary conservative surgery, with an added predictive value for the long-term outcome of the disease. Actually the best efficacy target for neoadjuvant therapy is expressed as pathological complete response (pCR). The predictive value 
Table 2 Taxanes and their combinations recommended by NCCN, ESMO, and AIOM guidelines for triple-negative BC

\begin{tabular}{lll}
\hline NCCN $^{16}$ & ESMO' & AIOM \\
\hline Monotherapy & Monotherapy (without extensive visceral & Monotherapy \\
Paclitaxel & involvement/symptomatic) & Paclitaxel \\
Docetaxel & Weekly paclitaxel & Docetaxel \\
Nab-paclitaxel & Weekly docetaxel or q36 & Nab-paclitaxel \\
& Nab-paclitaxel & \\
Combinations & Combinations (with extensive visceral & Combinations \\
Docetaxel + capecitabine & involvement/symptomatic) & Anthracycline + taxane \\
Gemcitabine + paclitaxel & Anthracycline + taxane (paclitaxel or docetaxel) & (paclitaxel or docetaxel) \\
Paclitaxel + bevacizumab & Docetaxel + capecitabine & Docetaxel + capecitabine \\
& Paclitaxel + gemcitabine & Paclitaxel + gemcitabine \\
& Paclitaxel + vinorelbine & Docetaxel + gemcitabine \\
& Paclitaxel + carboplatin & Paclitaxel + bevacizumab \\
\hline
\end{tabular}

Abbreviations: AIOM, Associazione Italiana di Oncologia Medica; ESMO, European Society for Medical Oncology; NCCN, National Comprehensive Cancer Network; $\mathrm{q} 3 \mathrm{w}$, every 3 weeks; BC, breast cancer.

of $\mathrm{pCR}$ as a surrogate for long-term clinical benefit has been recently confirmed by the retrospective pooled analysis of Cortazar et al. ${ }^{18}$ This meta-analysis was based on the pCR, overall response rate (ORR), and event-free survival (EFS) data of 12 international clinical trials on a total 11,550 patients. The analysis compared the three main definitions of pCR in order to establish their association with long-term efficacy: ypT0 ypN0 (no invasive and in situ tumor in the breast and auxiliary lymph nodes); ypT0/is ypN0 (no invasive tumor in the breast and auxiliary lymph nodes, independent of the presence of in situ ductal carcinoma); and ypT0/is ypN0/is (no invasive tumor in the breast, independent of the presence of in situ ductal carcinoma or lymph nodes involvement). The retrospective analysis showed that complete tumor eradication (breast and lymph nodes) (ypT0 ypN0 or ypT0/is ypN0 pCR) was strongly associated to the improvement of EFS and OS as compared with tumor eradication in the breast only (ypN0/is). The better combination between pCR and long-term effect was observed in patients with an aggressive tumor (TNBC; high-grade; ER/PgR-positive, HER2-negative; HER2-positive; and ER- and PgR-negative). Authors also stated in the paper that "pooled analysis could not validate $\mathrm{pCR}$ as a surrogate end point for improved EFS and OS" and that the potential explanation could be the heterogeneous BC subtypes in the examined trials. ${ }^{19}$

These results were confirmed by a further analysis of pooled data showing that the association between $\mathrm{pCR}$ and long-term outcome is particularly evident in patients with aggressive BCs. ${ }^{20,21}$

Several studies on neoadjuvant therapy confirmed the sensitivity of TNBC to cytotoxic drugs, as well as the importance of taxane-based chemotherapy. Rouzier et $\mathrm{al}^{22}$ evaluated the molecular-based chemosensitivity in 82 patients treated with anthracyclines and taxanes neoadjuvant therapy, and a pCR was observed in $45 \%$ of BL tumors and in $6 \%$ of luminal tumors (A and B).

An MD Anderson Cancer Center study ${ }^{23}$ evaluated 1,118 patients $(23 \%$ with TNBC) treated with neoadjuvant therapy. The pCR rates were significantly higher in TNBC treated with anthracyclines-based regimens. Anthracycline- and taxanebased regimens were more active, but both PFS and 3-year OS were significantly worse in TNBC (hazard ratio [HR] 1.86, 95\% confidence interval [CI] 1.39-2.50, $P<0.0001$; and HR 2.53, 95\% CI 1.77-3.57, $P<0.0001$, respectively). Patients with TNBC with residual disease had a poorer outcome that did those with non-TNBC tumors (3-year DFS rate $68 \%$ vs $88 \%)(P=0.0001)$. In patients with $\mathrm{pCR}$, both PFS and OS were no different between TNBC and other types of tumors (Figure 1).

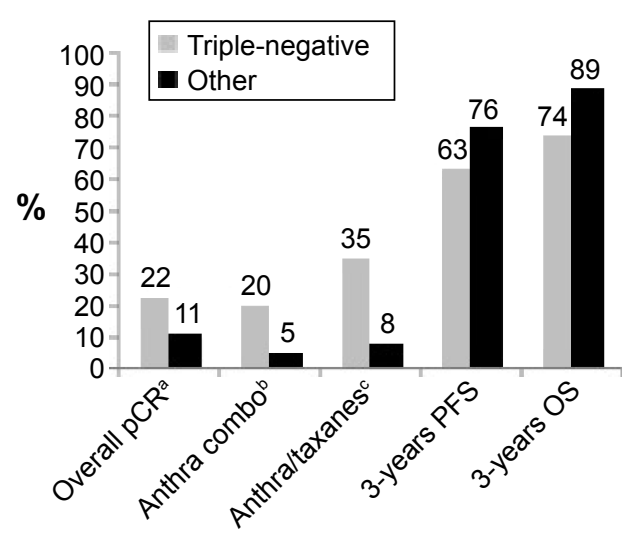

Figure I Effect of neoadjuvant chemotherapy in data of triple-negative BCs vs nontriple-negative $\mathrm{BCs} .^{23}$

Notes: ${ }^{a} P=0.034 ;{ }^{b} P=0.0001 ;{ }^{c} P=0.007$.

Abbreviations: Anthra, anthracycline; OS, overall survival; Other, non-triplenegative tumors; PCR, pathological complete response; PFS, progression-free survival. 
A similar study ${ }^{24}$ carried out in the same center on 1,731 patients treated with neoadjuvant anthracycline and taxane regimens reported an overall $\mathrm{pCR}$ rate of $13 \%$. In the 317 TNBC patients, the $\mathrm{pCR}$ rate was $22.4 \%$. In this group, $\mathrm{pCR}$ seemed to be a strong predictive factor of long-term survival, with $84 \%$ of patients still alive at 10 years vs $59 \%$ in the case of residual disease.

In a retrospective Japanese study, among 151 patients treated with anthracycline- and taxane-based neoadjuvant therapy, TNBC (14\%) had a pCR rate higher than did the non-TNBC tumors ( $38 \%$ vs $12 \%))^{25}$

A study by the Istituto Europeo di Oncologia ${ }^{26}$ in 30 patients with TNBC, four cycles of epirubicin, cisplatin, and continuous-infusion fluorouracil followed by three cycles of weekly paclitaxel achieved an objective response in 26 cases ( $86 \%$ ) and a pCR in 12 cases (40\%). A total 26 patients (86\%) underwent conservative surgery, and the 2-year DFS was $87.5 \%$.

The GeparDuo ${ }^{27,28}$ study evaluated the pCR rate in 913 women randomized to neoadjuvant doxorubicin and docetaxel for four cycles or doxorubicin and cyclophosphamide (AC) for four cycles followed by docetaxel for four cycles. The overall pCR rate was $10.6 \%$ ( $7 \%$ with the two-drug regimen and $14.3 \%$ with the triplet one). It should be noted that GeparDuo also tested four vs eight cycles of chemotherapy. Either way, the probability of pCR was three times higher in the endocrine receptor-negative tumors vs the endocrine receptor-positive subgroup $(22.8 \%$ vs $6.2 \%)$. The trial I-SPY ${ }^{29}$ evaluated 190 patients treated with neoadjuvant anthracyclines and taxanes: in the subgroup of TNBCs (28\%), the pCR rate was $33 \%$, significantly higher than that observed in HER2-negative and ER/PgR-positive tumors (10\%).

The efficacy of taxane-based neoadjuvant therapy was further confirmed by more recent trials. Wu et a ${ }^{30}$ evaluated the efficacy of neoadjuvant therapy with docetaxel plus epirubicin, and the OS in 54 patients with TNBC and in 195 patients with non-TNBC. A pCR was observed in $25.9 \%$ of TNBCs, significantly higher than in the other subtypes $(P=0.019)$. However, patients with TNBC with residual disease had a shorter 5-year DFS and OS vs patients with nonTNBC. In the subgroup with $\mathrm{pCR}$, survival was equivalent between the two groups, similarly to data previously reported by the MD Anderson group. ${ }^{23}$

Sakuma et al ${ }^{31}$ evaluated 44 patients with TNBC treated with anthracycline- and taxane-based neoadjuvant therapy, and reported a pCR in $36 \%$ of cases with a long-term outcome significantly better that that with residual disease.

The use of angiogenesis inhibitors in TNBC is supported by the highly proliferative nature of this tumor and by the importance of VEGF for its microvascular growth, ${ }^{32}$ and bevacizumab could play a role in the neoadjuvant setting. ${ }^{33}$ The recent Phase II KCSG BR-0905 trial ${ }^{34}$ evaluated the addition of bevacizumab to neoadjuvant docetaxel and carboplatin in 45 patients with TNBC. Also, in this study, the pCR rate was high (42\%), with a clinical response rate of $96 \%$. This allowed a conservative surgery in 35 cases (78\%). The Phase III GeparQuinto tria ${ }^{35}$ compared epirubicin and cyclophosphamide followed by docetaxel with or without bevacizumab in 1,948 HER2-negative BC patients, with an overall pCR rate (breast and nodes) of $18.4 \%$ with bevacizumab vs $19.9 \%$ for controls $(P=0.04)$. Among the 663 patients with TNBC, pCR rates were $39.3 \%$ with bevacizumab vs $27.9 \%$ in controls, and the difference was highly significant (odds ratio [OR] 1.67, 95\% CI 1.21-2.31, $P=0.003)$. Results in the ER/ PgR-positive population were not as good, with or without bevacizumab, with a pCR rate of $7.8 \%$ and $7.7 \%$, respectively (OR $0.99,95 \%$ CI $0.66-1.50, P=1.00$ ). It should be noted that the test for interaction showed just a trend to significance.

The New England Journal of Medicine published a report by Bear et $\mathrm{al}^{36}$ of another trial of neoadjuvant chemotherapy with or without bevacizumab, the NSABP B-40 study. This Phase III randomized trial assigned 1,206 patients with HER2-negative BC to receive docetaxel $\left(100 \mathrm{mg} / \mathrm{m}^{2}\right.$ every 21 days) or docetaxel $\left(75 \mathrm{mg} / \mathrm{m}^{2}\right.$ day 1) plus capecitabine ( $825 \mathrm{mg} / \mathrm{m}^{2}$ twice a day days 1 to 14$)$ or docetaxel $\left(75 \mathrm{mg} / \mathrm{m}^{2}\right.$ day 1) plus gemcitabine $\left(1,000 \mathrm{mg} / \mathrm{m}^{2}\right.$ days 1 and 8$)$ for four cycles. All regimens were followed by AC for a further four cycles. All patients were also randomized to receive bevacizumab $(15 \mathrm{mg} / \mathrm{kg})$ or not for the first six cycles of chemotherapy. Results showed first of all that the addition of capecitabine and gemcitabine did not improve the rate of $\mathrm{pCR}$ vs docetaxel alone and showed increased toxicity and that the toxicity of bevacizumab was manageable and as expected from previous trials and, significantly increased the overall pCR rate $(34.5 \%$ vs $28.2 \%)(P=0.02)$. The multiple logistic regression model showed that TNBC subtype, high grade, and smaller tumor size were associated with higher rates of pCR in the breast, but when considering the pCR in breast and nodes, the addition of bevacizumab was significantly related to a better result in hormone receptor-positive tumors only.

In the randomized Phase II GeparSixto trial, ${ }^{37} 315$ patients with TNBC were treated with weekly paclitaxel plus nonpegylated liposomal doxorubicin (once a week for 18 weeks) and bevacizumab every 3 weeks and were randomized to receive weekly carboplatin (area under the time-concentration curve [AUC] $=2$ ) or not. The pCR (ypT0ypN0) rate was $16 \%$ higher with the addition of carboplatin (53.2\% vs $36.9 \%)$ $(P=0.005)$. The toxicity was also significantly higher, with 
$53 \%$ discontinuation (41\% with AUC reduced to 1.5). Data on the $B R C A$ mutation are not yet available in order to assess the correct role of carboplatin.

At the ASCO 2015 meeting, further interesting data from the GeparSixto trial were presented, ${ }^{38}$ showing that the addition of carboplatin to taxane and anthracycline increased the pCR rate from $45.2 \%$ to $64.9 \%$ in TNBC with homologous recombination deficiency. In tumors without deficiency, carboplatin did not improve the $\mathrm{pCR}$ rate.

Other data on the role of bevacizumab added to neoadjuvant chemotherapy were also recently reported from the Cancer and Leukemia Group B (CALGB) 40603 trial. ${ }^{39}$ A standard chemotherapy plus carboplatin and bevacizumab obtained a pCR rate higher $(60 \%)$ vs the same without bevacizumab (49\%) or standard chemo alone (+/- bevacizumab: $43 \%$ vs $39 \%$ ). The addition of carboplatin led to significant but small improvement in $\mathrm{pCR}$ rate, at the price of increased toxicity. At the ASCO 2015 meeting, an update of this trial reported a rate of conversion to the possibility of breast conservative surgery in favor of the bevacizumab arm of $42 \%$ in TNBC. ${ }^{40}$

In June 2015, Earl et $\mathrm{al}^{41}$ reported results of the multicenter British ARTemis Phase III trial. Between 2009 and 2013, 880 patients with HER2-negative early BC (tumor size $>20 \mathrm{~mm}$, clinically positive or negative Nodes) were randomized to three cycles of docetaxel ( $100 \mathrm{mg} / \mathrm{m}^{2}$ every 21 days) followed by three cycles of 5-Fluoruracile, Epirubicine at $100 \mathrm{mg} / \mathrm{sqm}$, Cyclophosphamide regimen every 21 days, with or without four cycles of bevacizumab $(15 \mathrm{mg} / \mathrm{kg})$. The primary end point was pCR (tumor and nodes). Results showed a significant increase of pCR with the addition of bevacizumab $(22 \%$ vs $17 \%)(P=0.03)$. The most important result of this trial is the great added value of bevacizumab in the TNBC population (pCR 45\% vs 31\%) $(P<0.0001)$ as compared with the ER-positive HER2-neg population (pCR 7\% vs 6\%). ARTemis results are consistent with those of GeparQuinto ${ }^{35}$ and CALGB $40603^{39}$ and could also explain the different results for the HER2-negative ER-positive population in the NSABP B40 trial, ${ }^{36}$ where the cutoff for the ER-positive population was very low ( $1 \%$ of positive cells) compared with both GeparQuinto and CALGB 40603 (cutoff 10\%).

The role of pCR as a surrogate end point for DFS and OS has so far not been defined, and the answer will be possible from an extensive meta-analysis of long-term results of the Phase III randomized trials.

\section{The adjuvant setting}

Studies in adjuvant setting also confirmed the activity and relevance of taxanes in TNBCs. Hayes et al retrospectively analyzed the histological samples of 1,322 patients enrolled in the CALGB 9344 study $^{42}$ in order to evaluate the role of HER2 status on clinical end points. Patients were divided in four groups: endocrine receptor- and HER2-negative (TNBC); endocrine receptor- and HER2-positive; endocrine receptor-positive and HER2-negative; endocrine receptor-negative and HER2-positive. Adding paclitaxel to anthracycline improved DFS both in HER2-positive patients, independently from endocrine receptor status, and in TNBC patients. No clinical benefit was observed in HER2-negative and endocrine receptor-positive tumors. This explorative analysis suggests that paclitaxel added to the adjuvant regimen significantly improves the outcome in TNBCs.

The study of Sparano et $\mathrm{al}^{43}$ conducted on 4,950 patients, evaluated in the adjuvant setting the efficacy of AC followed by weekly or 3-weekly (q3w) docetaxel or paclitaxel. The results showed an improvement both in DFS and 5-year OS with weekly paclitaxel with respect to $\mathrm{q} 3 \mathrm{w}$ paclitaxel. In TNBCs, the benefit of conventional weekly paclitaxel in term of DFS was $37 \%$ higher than the q3w regimen.

Other studies also evaluated anthracycline- and taxanebased adjuvant therapy in TNBC. The Breast Cancer International Research Group (BCIRG) 001 study ${ }^{44}$ compared docetaxel plus doxorubicin plus cyclophosphamide vs fluorouracil plus doxorubicin plus cyclophosphamide, showing that taxane was able to increase the efficacy in the TNBC cohort. Similar results were reported in a multicenter randomized Phase III study by Loesch et $\mathrm{al}^{45}$ comparing AC followed by paclitaxel with doxorubicin and paclitaxel followed by weekly paclitaxel in high-risk BC patients.

Finally, a recent meta-analysis of 14 randomized Phase III studies on 25,067 patients $^{46}$ evaluated the impact of a docetaxel-based adjuvant therapy on DFS and OS in early BC. The improvement in survival obtained with docetaxelbased regimens with respect to docetaxel-free regimens was observed, not only in the general population but also, in several subgroups, TNBC included.

All the above cited data confirm the high activity of taxanes in TNBC; however, at the ASCO 2015 meeting, interesting data from the adjuvant Phase III TITAN trial were reported. ${ }^{47}$ In this trial, 614 early TNBC patients were randomized to adjuvant $\mathrm{AC}$ for four cycles followed by ixabepilone $\mathrm{q} 3 \mathrm{w}$ for four cycles or weekly paclitaxel for 12 cycles. At a median follow up of 48 months, no difference was found between the two arms in 5-year DFS (87\% vs $85.4 \%)$ or OS (92.3\% vs $90.2 \%)$. Both regimens performed well, with different toxicity profile: ixabepilone had lower rate of neurotoxicity and fewer dose reductions.

The open-label, randomized Phase III BEATRICE study assessed the addition of bevacizumab to chemotherapy in 
the adjuvant setting for 2,591 women with TNBC. The primary analysis showed that invasive DFS (IDFS) events were observed in $16 \%$ of patients treated with chemotherapy alone compared with $14 \%$ of those treated with chemotherapy plus bevacizumab $(P=0.18)$; the 3 -year IDFS was $82.7 \%$ and $83.7 \%$, respectively. After 200 deaths, no difference in OS was noted between the groups $(P=0.23)$. The addition of bevacizumab was associated with increased incidences of Grade 3 or worse hypertension, severe cardiac events, and treatment discontinuation. For these reasons, the authors stated that bevacizumab cannot be recommended as adjuvant treatment in unselected patients with TNBC. ${ }^{48}$

\section{The metastatic setting}

Conventional taxanes have a central role in the treatment of metastatic BC, based on several evidences of their benefits on clinical outcomes, such as OS, time to progression (TTP), and ORR. ${ }^{49}$

Even if conventional taxanes demonstrated to be more active in endocrine receptor-negative tumors and are indicated in the first-line treatment of TNBC (although a specific benefit in this setting was not observed), it should be considered that they are commonly used in adjuvant therapy and cannot be rechallenged in case of short disease-free interval (<12 months). ${ }^{4,50}$

The duration of response to chemotherapy of TNBC is usually short, as demonstrated by a retrospective analysis of 111 cases treated with monotherapy or combinations. ${ }^{51}$ The mean duration of the response was 12 weeks after first-line treatment, 9 weeks after second-line, and 4 weeks after thirdline treatment. For this reason, some recent studies evaluated new first-line therapeutic regimens, combining taxanes with other cytotoxic drugs or new molecules.

The role of bevacizumab in metastatic disease was also explored in several Phase III trials. A meta-analysis of the three main Phase III studies of bevacizumab combined with first-line chemotherapy, showed an increase of PFS vs chemotherapy alone ( 8.1 vs 5.4 months) in 621 patients with TNBC. ${ }^{52}$ In the RIBBON-2 study, ${ }^{53}$ patients progressed after first-line chemotherapy and treated with second-line bevacizumab with or without chemotherapy were enrolled. Recently, a subanalysis of 159 (23\%) cases of TNBCs in the RIBBON-2 study, most treated with taxanes, reported a median PFS of 6 months with bevacizumab plus chemotherapy vs 2.7 months with chemotherapy alone $(P=0.0006)$; the median OS was 17.9 vs 12.6 months $(P=0.0534)$, and the ORR was $41 \%$ vs $18 \%(P=0.0078)$. The Phase III IMELDA Trial was published by Gligorov et al ${ }^{54}$ in late 2014 , mainly based on the meta-analysis of Gennari et $\mathrm{al}^{55}$ which found a first-line chemotherapy until progression led to a longer PFS and a small but appreciable increase in OS. ${ }^{55}$ In the $\mathrm{AVADO}^{52}$ trial where the response rate was very high, but a prolonged treatment with docetaxel was unrealistic because of cumulative toxicity. The openlabel Phase III IMELDA trial investigated the combination of capecitabine and bevacizumab after initiation of docetaxel and bevacizumab. Previously untreated HER2-negative metastatic BC patients were treated with three to six cycles of bevacizumab $(15 \mathrm{mg} / \mathrm{kg})$ and docetaxel (75-100 mg/m²) every 21 days. Patients with progressive disease were excluded, and responders (complete or partial response [CR or PR]) or patients with stable disease were randomized to maintenance with bevacizumab or bevacizumab plus capecitabine $\left(1,000 \mathrm{mg} / \mathrm{m}^{2}\right.$ twice daily days 1-14 q3w, until disease progression (PD), unacceptable toxicity, or consent withdrawal. Bevacizumab and capecitabine significantly improved overall median PFS (11.9 vs 4.3 months) (HR 0.38, $P<0.001)$ and OS (39 vs 23.7 months) (HR $0.43, P<0.001$ ), without unexpected safety problems. In the TNBC population, the median PFS was 7.6 months with the combination and 3.6 months with bevacizumab alone (HR 0.48). At the 2014 San Antonio Symposium, the OS in prespecified subgroups was presented, confirming the very good result in the TNBC population, with a death risk reduction of $53 \%$ (HR 0.47 ) compared with $57 \%$ in the overall population and with a 2 -years OS of $62 \% .{ }^{54}$

Fan et $\mathrm{al}^{56}$ evaluated the efficacy of docetaxel combined with cisplatin or capecitabine in the first-line treatment of patients with metastatic TNBC. The ORR was significantly higher in patients treated with docetaxel plus cisplatin than with docetaxel plus capecitabine (63\% vs $15.4 \%)(P=0.001)$, as were the median PFS (10.9 vs 4.8 months) $(P<0.001)$ and median OS (32.8 vs 21.5 months) $(P=0.027)$, confirming the role of platinum in TNBC.

At the 2014 San Antonio Symposium, Tutt et al ${ }^{57}$ presented results from the randomized Phase III TNT trial comparing carboplatin $(\mathrm{AUC}=6)$ with docetaxel $\left(100 \mathrm{mg} / \mathrm{m}^{2}\right)$, both every 21 days for six cycles, as first-line treatment in 376 patients with advanced TNBC or BRCA1/2-positive $\mathrm{BC}$. The primary end point was the objective response rate in the intent-to-treat population. Of note, nearly all cancers with $B R C A 1$ mutations are triple negative, whereas tumors with $B R C A 2$ mutations can be either ER positive or triple negative. So, in the BRCA2 population of this study, there were also some ER-positive patients.

The TNT trial was based on the hypothesis that because $B R C A 1 / 2$ germline mutations produce $\mathrm{BCs}$ that have defects in homologous recombination DNA repair, carboplatin would 
be lethal to cells with germline and somatic mutations in $B R C A 1 / 2$. In other words, carboplatin might be an especially good therapy in terms of exploiting the defect in homologous recombination DNA repair, and this is why patients with $B R C A 1 / 2$ mutations were included with TNBC patients. The results showed no significant difference in response rates between carboplatin and docetaxel in the overall patient group or in patients who received either agent as first-line therapy and then crossed over to the other agent as secondline treatment.

The only significant difference was in patients with $B R C A 1 / 2$ germline mutations (response rate with carboplatin $68 \%$ vs $33 \%$ with docetaxel) $(P=0.03)$. Similarly, PFS was 6.8 months vs 4.5 . This is the outstanding result of this study, showing that platinum compounds could be more active than taxanes in patients with $B R C A 1 / 2$ germline mutations. In patients with wild-type $B R C A 1 / 2$, there was a nonsignificant trend for a higher response rate with docetaxel. No difference was found in PFS or OS.

A Japanese study, ${ }^{58}$ interesting despite the low number of patients, evaluated the efficacy of the combination gemcitabine plus paclitaxel in 56 patients with metastatic $\mathrm{BC}$, including 14 cases of TNBC. In the general population, the ORR was $44.6 \%$, median TTP was 8.6 months, and median OS was 27.1 months, whereas in the TNBC population, the ORR was 35.7\% and median TTP was 6 months.

An interesting recent Phase I study ${ }^{59}$ evaluated the efficacy and safety of olaparib, an oral PARP inhibitor, associated to paclitaxel in first- or second-line treatment in 19 patients with TNBC. Despite a good global efficacy (37\% of confirmed partial responses), the combination of olaparib plus weekly paclitaxel had an unexpected higher neutropenia rate, even after secondary prophylaxis.

Approximately $10 \%$ to $15 \%$ of TNBC express androgen receptor (AR). ${ }^{13}$ The LAR subtype of TNBC actually is a Luminal one, rich in $\mathrm{AR},{ }^{13}$ and this is the rationale for an antiandrogen therapy. Enzalutamide is a potent AR inhibitor, but AR expression does not necessarily mean sensitivity to endocrine treatment. At the ASCO 2015 meeting, Parker et $\mathrm{al}^{60}$ reported results of a randomized study in which a new gene profile was able to predict the benefit from treatment with enzalutamide in metastatic TNBC. Actually, 50\% of patients with the positive diagnostic profile obtained $39 \%$ of clinical benefit rates at 16 months and $36 \%$ at 24 months, versus $11 \%$ and $6 \%$ respectively of patients with the negative diagnostic profile. This interesting result may be useful for a more targeted selection of TNBC patients suitable for an antiandrogen treatment in future trials.
In conclusion, the main reason of failure in metastatic $\mathrm{BC}$ is resistance to the standard drugs, which can be intrinsic or acquired. Patients with disease progression or resistance could not have a cross-resistance with other drugs, such as capecitabine, gemcitabine, vinorelbine, eribulin, or nabpaclitaxel, which demonstrated their efficacy in patients with advanced $\mathrm{BC}$ pretreated with anthracyclines and/or taxanes. $^{32}$

\section{Nab-paclitaxel}

Nab-paclitaxel is a nanoparticle with median size $130 \mathrm{~nm}$, solvent-free. ${ }^{61,62}$ Nanotechnology utilizes the natural properties of albumin to potentiate the selective uptake of paclitaxel in tumors and for targeting the drug directly into the cancer cells. Preclinical studies showed that nab-paclitaxel achieves a 33\% higher tumor uptake vs conventional paclitaxel but lower uptake in normal tissue and plasma; furthermore, these studies demonstrated a lower toxicity in animals, a higher activity in animal models with xenograft tumors (breast, lung, ovarian, prostate, and colon), and that nab-paclitaxel is four times more efficient in crossing layers of endothelial cells. $^{63-65}$

This unique and innovative mechanism of transport of nab-paclitaxel allows a higher concentration of the active drug in the tumor, better efficacy, and safety vs those for both conventional paclitaxel and docetaxel observed in clinical trials in metastatic $\mathrm{BC}$.

\section{Nab-paclitaxel in the metastatic setting}

The Phase III pivotal study by Gradishar et a ${ }^{66}$ evaluated the efficacy of nab-paclitaxel $\left(260 \mathrm{mg} / \mathrm{m}^{2}\right.$ intravenously [IV] q3w without premedication) vs conventional paclitaxel $\left(175 \mathrm{mg} / \mathrm{m}^{2}\right.$ IV with premedication) in 454 patients with metastatic BC. Nab-paclitaxel resulted significantly superior in ORR (33\% vs $19 \%)(P=0.001)$ and in TTP (23 vs 16.9 weeks $)(P=0.006)$ vs conventional paclitaxel; OS was significantly higher in patients treated with nab-paclitaxel beyond the first line than in patients treated with conventional paclitaxel (56.4 vs 46.7 weeks $)(P=0.024)$. As far as safety is concerned, the grade $3 / 4$ neutropenia rate was significantly lower with nab-paclitaxel (34\% vs 54\%) $(P<0.001)$, and Grade 4 neutropenia alone was even better ( $9 \%$ vs $22 \%)(P<0.001)$, despite an almost double dose of paclitaxel ( $49 \%$ higher); the grade 3 sensitive neuropathy rate was higher $(10 \%$ vs $2 \%)(P<0.001)$ but rapidly reversed to a $\leq 2$ grade than did conventional paclitaxel. This study shows an important benefit of $\mathrm{q} 3 \mathrm{w}$ nab-paclitaxel over q3w conventional paclitaxel, with an improved therapeutic index and the lack of premedication with steroids. 


\section{About the optimal schedule of conventional paclitaxel}

It is widely accepted that weekly paclitaxel is a "different treatment" compared with the q3w schedule, in any setting. ${ }^{67}$ In the neoadjuvant setting, the weekly schedule was superior, with a $28.2 \%$ pCR vs $15.7 \%(P=0.02) ;{ }^{68}$ in the adjuvant setting, by the already cited trial of Sparano et $\mathrm{al}^{4}{ }^{43}$ the comparison of weekly to q3w paclitaxel (and docetaxel) after four cycles of AC showed a significant advantage in DFS in favor of weekly paclitaxel (HR 1.27, $P=0.006$ ), in particular in TNBC. In the metastatic setting, weekly paclitaxel was also significantly superior to the $\mathrm{q} 3 \mathrm{w}$ schedule ${ }^{69}$ in response rate $(42 \%$ vs $29 \%)$ (OR 1.75, $P=0.0004$ ), median TTP ( 9 vs 5 months) (HR 1.43, $P<0.0001$ ), and median OS (24 vs 12 months) (HR 1.28, $P=0.0092)$, at an expected price of a significant increase in Grade 3 neurotoxicity ( $824 \%$ vs $12 \%)(P=0.0003)$, which was defined as the treatment-limiting toxicity.

Nowadays the $\mathrm{q} 3 \mathrm{w}$ conventional paclitaxel schedule is rarely used, and the preferred schedules for conventional taxanes are weekly paclitaxel or $\mathrm{q} 3 \mathrm{w}$ docetaxel.

An open-label, multicenter, randomized Phase II study ${ }^{70}$ evaluated the efficacy and safety of three nab-paclitaxelbased regimens $\left(300 \mathrm{mg} / \mathrm{m}^{2} \mathrm{q} 3 \mathrm{w}, 100 \mathrm{mg} / \mathrm{m}^{2}\right.$ weekly, or $150 \mathrm{mg} / \mathrm{m}^{2}$ weekly) vs docetaxel $100 \mathrm{mg} / \mathrm{m}^{2} \mathrm{q} 3 \mathrm{w}$ in the first-line treatment of 302 patients with metastatic BC. The nab-paclitaxel $150 \mathrm{mg} / \mathrm{m}^{2}$ weekly schedule obtained significantly longer PFS than did docetaxel by both independent (12.9 vs 7.5 months $)(P=0.0065)$ and investigator (14.6 vs 7.8 months) $(P=0.012)$ assessment. According to the independent radiologist review, both schedules of $150 \mathrm{mg} /$ $\mathrm{m}^{2}(49 \%)$ and $100 \mathrm{mg} / \mathrm{m}^{2}$ (45\%) weekly of nab-paclitaxel demonstrated a higher ORR vs docetaxel (35\%), but this did not reach statistical significance. The evaluation of ORR by investigators showed a statistically significant difference between the weekly schedules of nab-paclitaxel and docetaxel (74\% with $150 \mathrm{mg} / \mathrm{m}^{2}$ and $62 \%$ with $100 \mathrm{mg} / \mathrm{m}^{2}$ vs 39\%) $(P<0.05)$. The final analysis of OS of this study, published by Gradishar et al in 2012, ${ }^{71}$ showed a median OS of 33.8 months with weekly nab-paclitaxel $150 \mathrm{mg} / \mathrm{m}^{2}$ vs $22.2,27.7$, and 26.6 months, respectively, with weekly nab-paclitaxel $100 \mathrm{mg} / \mathrm{m}^{2}$ and $300 \mathrm{mg} / \mathrm{m}^{2} \mathrm{q} 3 \mathrm{w}$, and docetaxel $100 \mathrm{mg} / \mathrm{m}^{2} \mathrm{q} 3 \mathrm{w}(P=0.047)$.

A trend toward a longer OS was noted in all the patients subgroups, independent from age ( $<65$ vs $\geq 65$ years), type of metastatic site (visceral vs not), number of visceral lesions ( $<5 \mathrm{vs} \geq 5$ ), and menopausal status. The best clinical response was already observed after two cycles of treatment with weekly nab-paclitaxel 150 or $100 \mathrm{mg} / \mathrm{m}^{2}$ vs five cycles of docetaxel $(P<0.001)$, highlighting the quick response of this new drug. Further, the median number of cycles administrated with weekly nab-paclitaxel $150 \mathrm{mg} / \mathrm{m}^{2}$ was higher than with docetaxel (eight vs ten). The weekly dose of $150 \mathrm{mg} / \mathrm{m}^{2}$ of nab-paclitaxel could be the most effective dosage, from a clinical point of view, for previously untreated and fit patients. ${ }^{71}$

A retrospective analysis of previous studies (CA012 and CA024) $)^{72}$ evaluated the efficacy of nab-paclitaxel in patients with poor prognostic factors: dominant visceral metastasis and short DFS. In the first study (CA012), the ORR was higher in patients treated with nab-paclitaxel vs those treated with conventional paclitaxel both in dominant visceral metastasis ( $42 \%$ vs $23 \%)(P=0.022)$ and in short DFS (43\% vs 33\%) $(P=0.417)$. Also, in the second study (CA024), patients treated with weekly nab-paclitaxel showed a better ORR than did patients treated with docetaxel, significantly higher in the cases of dominant visceral metastases.

PFS and OS showed a similar trend, but a statistically significant difference was observed only in the second study, which showed PFS in dominant visceral metastasis (13.1 months for nab-paclitaxel $150 \mathrm{mg} / \mathrm{m}^{2}$ vs 7.8 months for docetaxel $[P=0.019]$ and 7.5 months for nab-paclitaxel $\left.100 \mathrm{mg} / \mathrm{m}^{2}[P=0.010]\right)$. The results of this analysis suggest that nab-paclitaxel is a therapeutic option also for patients with very aggressive disease.

The study of Blum et $\mathrm{al}^{73}$ demonstrated the efficacy of monotherapy with weekly nab-paclitaxel at $100 \mathrm{mg} / \mathrm{m}^{2}(\mathrm{n}=106)$ or $125 \mathrm{mg} / \mathrm{m}^{2}(\mathrm{n}=75)$ in patients with metastatic BC heavily pretreated with conventional taxanes. The ORR was $14 \%$ and $16 \%$ with $100 \mathrm{mg} / \mathrm{m}^{2}$ and $125 \mathrm{mg} / \mathrm{m}^{2}$, respectively; stable disease for more than 16 weeks was observed in $12 \%$ and in $21 \%$ of cases, respectively. Median PFS and OS were 3 and 9.2 months with $100 \mathrm{mg} / \mathrm{m}^{2}$, and 3.5 and 9.1 months with $125 \mathrm{mg} / \mathrm{m}^{2}$.

Nab-paclitaxel, administered to patients with metastatic $\mathrm{BC}$ pretreated with conventional taxanes, has a significant antitumor activity and is well tolerated. Further evidence of efficacy of nab-paclitaxel in patients previously treated with conventional taxanes is the recently published prospective, multicenter Italian study that aimed to evaluate the efficacy and safety of nab-paclitaxel $260 \mathrm{mg} / \mathrm{m}^{2} \mathrm{q} 3 \mathrm{w}$ in second-line treatment of 52 HER2-negative, taxane-pretreated metastatic BC patients. The ORR was $48 \%$ (13.5\% of complete response), the overall clinical benefit rate was $77 \%$, and the median PFS was 8.9 months. Adverse events were expected and manageable, with good patient compliance and quality of life even after long-term treatment. ${ }^{74}$ 
Some clinical trials evaluated the combination of nabpaclitaxel with other chemotherapy drugs commonly used in first-line treatment for metastatic BC (ie, capecitabine and gemcitabine). Schwartzberg et $\mathrm{al}^{75}$ analyzed the efficacy of weekly nab-paclitaxel at $125 \mathrm{mg} / \mathrm{m}^{2}$ plus capecitabine $825 \mathrm{mg} / \mathrm{m}^{2}$ twice daily orally for 15 days per cycle in 46 patients with metastatic BC. The ORR was $61 \%$ (complete response [clinical or radiological] $4 \%$ and partial response $57 \%$ ), seven patients had a stable disease ( $\geq 24$ weeks), with an overall clinical benefit of $76.1 \%$. The median PFS was 10.6 months and median OS was 19.9 months. Another open-label Phase II study $^{76}$ evaluated the combination of weekly nab-paclitaxel $\left(125 \mathrm{mg} / \mathrm{m}^{2}\right)$ and gemcitabine $\left(1,000 \mathrm{mg} / \mathrm{m}^{2}\right)$ in 50 nonpretreated patients. Findings were that $8 \%$ and $42 \%$ of patients showed a complete and partial response, respectively. The median duration of the response was 6.9 months, the median PFS 7.9 months, and the median OS was not yet reached. The treatment was well-tolerated. An unplanned analysis of subgroups showed a clinical response in ten out of 13 patients (77\%), with TNBC vs 16 of other patients (44\%).

Even if it is not possible to draw conclusive consideration in this small subgroup of patients, these data suggest the possibility that TNBC could be particularly responsive to nab-paclitaxel-based regimens.

\section{Nab-paclitaxel and bevacizumab in the metastatic setting}

The combination of nab-paclitaxel and bevacizumab was investigated by several authors in the first-line treatment of TNBC. In 2010, Lobo et $\mathrm{al}^{77}$ published an open-label Phase II study of first-line treatment with weekly nab-paclitaxel $\left(150 \mathrm{mg} / \mathrm{m}^{2}\right)$, bevacizumab $(10 \mathrm{mg} / \mathrm{kg})$, and gemcitabine $\left(1,500 \mathrm{mg} / \mathrm{m}^{2}\right)$ in 30 patients with metastatic HER2-negative BC. The median PFS was 10.4 months and ORR was $75.9 \%$, including eight complete responses $(27.6 \%)$. In this trial, 13 patients $(44.8 \%)$ had TNBC. The results showed a good clinical response in this subgroup, with a complete response in five cases (38.4\%), a partial response in four cases (30.7\%), and stable disease in a further two cases $(6.9 \%)$. Finally, the 18 -month OS rate was $77.2 \%$ in the overall population and $82.5 \%$ (95\% CI 46.1\%-95.3\%) in TNBC patients. Eight patients $(27.6 \%)$ experienced a grade $3 / 4$ toxicity. Since firstline treatment with a triplet chemotherapy was demonstrated to be very active, with an acceptable toxicity, the authors suggested further evaluation of this combination.

Hamilton et $\mathrm{al}^{78}$ published, in 2013, the results of a multicenter Phase II study of the combination of nab-paclitaxel plus bevacizumab plus carboplatin in first-line treatment for
TNBC. Patients received weekly nab-paclitaxel $\left(100 \mathrm{mg} / \mathrm{m}^{2}\right)$ plus carboplatin (AUC 2) for three times in a cycle of 28 days and bevacizumab $(10 \mathrm{mg} / \mathrm{kg})$ at days 1 and 15 of the cycle. The treatment was continued until disease progression, unacceptable toxicity, or voluntary withdrawal from protocol. The primary end points were safety and tolerability; secondary end points were PFS, ORR, and clinical benefit. A total 34 patients, with median age 50 years (range: $30-76$ years) were enrolled; of these, $26(77 \%)$ were treated in the adjuvant setting with anthracyclines and taxanes, and $88 \%$ had visceral metastases.

Despite the limitation of the low number of patients, this study is very interesting because the triple combination was able to obtain encouraging results, with a median PFS of 9.2 months (95\% CI 7.8-25.1 months), and a 6-month and 9-month progression-free rate of $88 \%$ and $64 \%$ respectively. The ORR was $85 \%$, with $17.7 \%$ having complete response and a very high rate of clinical benefit (94\%) (Figure 2). The randomized Phase III CALGB 40502 study compared weekly nab-paclitaxel $150 \mathrm{mg} / \mathrm{m}^{2}$ or weekly ixabepilone $16 \mathrm{mg} / \mathrm{m}^{2}$ to weekly paclitaxel $90 \mathrm{mg} / \mathrm{m}^{2}$, all of them for 3 of 4 weeks and associated with bevacizumab, as first-line therapy for 783 patients with advanced $\mathrm{BC}$. The median PFS was 11 months for paclitaxel, 7.4 months for ixabepilone $(P<0.001)$, and 9.3 months for nab-paclitaxel $(P=0.054)$. In an explorative unplanned subgroup analysis of the TNBC population, no significant differences between the nab-paclitaxel plus bevacizumab and paclitaxel plus bevacizumab groups were observed (median PFS 7.4 and 6.5 months, respectively). ${ }^{79}$ It seems that the lack of superiority of nab-paclitaxel over paclitaxel in the CALGB study could be attributable to a suboptimal drug dose and imperfect knowledge of nab-paclitaxel pharmacokinetics in association with bevacizumab ${ }^{80}-$ the dose reductions and treatment interruptions were much higher

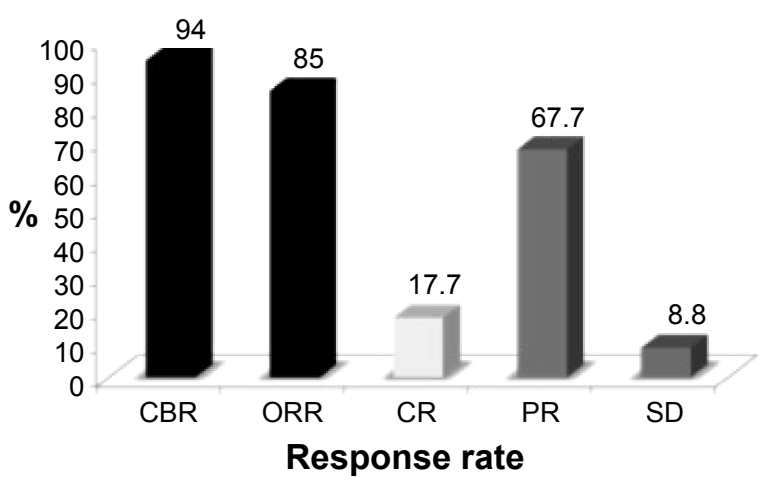

Figure 2 Efficacy parameters in patients with triple-negative BC treated with nabpaclitaxel/bevacizumab/carboplatin. ${ }^{70}$

Notes: CBR: 95\% Cl 80-99. ORR: 95\% Cl 69-95.

Abbreviations: $\mathrm{BC}$, breast cancer; $\mathrm{CBR}$, clinical benefit rate; $\mathrm{Cl}$, confidence interval; $\mathrm{CR}$, complete response; ORR, overall response rate; $\mathrm{PR}$, partial response; $\mathrm{SD}$, stable disease. 
in the nab-paclitaxel plus bevacizumab arm vs conventional paclitaxel plus bevacizumab.

The safety profile was very good: neutropenia and thrombocytopenia were the most frequent grade 3/4 adverse events (53\% and 18\% respectively). According to the authors, first-line treatment with the combination of nab-paclitaxel, bevacizumab, and carboplatin seems to be effective and welltolerated in patients with metastatic TNBC, with PFS, ORR, clinical benefit, and safety comparable with that observed with other standard first-line treatments.

\section{Nab-paclitaxel in the neoadjuvant setting}

The neoadjuvant setting is very important as stated before, in particular, for the still discussed but widely accepted value of pCR as a surrogate point for long-term outcome. ${ }^{18-21,81}$ In the past few years, many studies with nab-paclitaxel-based neoadjuvant regimens have been published.

\section{Nab-paclitaxel and bevacizumab in the neoadjuvant setting}

The efficacy and safety profile of the combination of nabpaclitaxel and bevacizumab was evaluated also in neoadjuvant therapy in the Phase II SWOG S0800 study. ${ }^{82}$ This study enrolled 215 patients with inflammatory BC (IBC) or locally advanced BC, comparing bevacizumab $(10 \mathrm{mg} / \mathrm{kg}$ IV every 14 days for 12 weeks) plus weekly nab-paclitaxel $100 \mathrm{mg} / \mathrm{m}^{2}$ for 12 weeks followed by AC (doxorubicin $69 \mathrm{mg} / \mathrm{m}^{2} \mathrm{IV}$ for six cycles every 14 days and pegfilgrastim $6 \mathrm{mg}$ subcutaneously) with nab-paclitaxel alone after or before AC. ${ }^{82}$ Based on its several clinical benefits in terms of efficacy and safety, the authors used nab-paclitaxel as the backbone of the study. The results showed that the combination of nab-paclitaxel plus AC was able to obtain a pCR rate higher than that of other nab-paclitaxel-free regimens $(21 \%$ vs 10\%-11\%). Nab-paclitaxel plus bevacizumab significantly increased the pCR in the intention-to-treat population (36\%), with the higher rate in hormone-negative patients (pCR 59\% vs $28 \%$ of controls). It is noteworthy that the combination nab-paclitaxel and bevacizumab was not associated with increased grade $3 / 4$ toxicity. ${ }^{82}$

Another interesting Phase II study of neoadjuvant treatment ${ }^{83}$ involved 42 patients with TNBCs $>2 \mathrm{~cm}$ treated with nab-paclitaxel at $100 \mathrm{mg} / \mathrm{m}^{2}$ was given on days 1,8 , and 15 , and carboplatin $(\mathrm{AUC}=6)$ day 1 , every 4 weeks for four cycles, followed by doxorubicin $60 \mathrm{mg} / \mathrm{m}^{2}$ and cyclophosphamide $600 \mathrm{mg} / \mathrm{m}^{2}$, "dose-dense" every 14 days. Bevacizumab $10 \mathrm{mg} / \mathrm{kg}$ was administered every two weeks with chemotherapy, and continued postoperatively for a total of 1 year. The pCR rate was very high: 53\% in breast and lymph nodes; the only severe toxicity was Grade $3(56 \%)$ and Grade 4 (24\%) neutropenia, preventable with granulocyte growth factors. These results are very important considering the triple-negative setting.

\section{Neoadjuvant nab-paclitaxel with other combinations}

One recent Phase II study ${ }^{84}$ in the neoadjuvant setting matched 30 patients with weekly nab-paclitaxel (125 mg) and 90 patients with conventional paclitaxel, both combined with carboplatin ( $\mathrm{AUC}=2$ ) and trastuzumab, in the HER2-positive population. The results were similar for the two taxanes with respect to pCR (nab-paclitaxel $26.7 \%$ vs paclitaxel $25.6 \%$, and $43.6 \%$ vs $39.6 \%$ with trastuzumab, respectively). Grade 4 neutropenia was higher with nabpaclitaxel. This study is small, as stated by the authors, with just two TNBC cases, but it confirms the study by Snider et $\mathrm{al}^{83}$ regarding the need of growth factors use when combining a taxane with carboplatin. The strength of this combination is the absence of anthracycline, which is interesting for cardiopathic patients. The authors cited, in the concluding remarks, several "ongoing large Phase III trials able to provide a definitive answer on the role of nab-paclitaxel in the neoadjuvant setting". We believe this recently happened with the reporting of the GeparSepto ${ }^{85}$ trial, in which there were 275 TNBCs.

\section{The GeparSepto study}

The GeparSepto (NCT01583426) ${ }^{85}$ neoadjuvant study compared weekly nab-paclitaxel (at the initial dose of $150 \mathrm{mg} / \mathrm{m}^{2} /$ week in the first 400 patients, amended for toxicity to $125 \mathrm{mg} / \mathrm{m}^{2} /$ week in the next 800 ), or conventional paclitaxel ( $80 \mathrm{mg} / \mathrm{m}^{2} /$ week) for 12 weeks, both followed by four cycles of epirubicin plus cyclophosphamide, in more than 1,200 patients with early BC (275 with TNBC). The results were presented at the 2014 San Antonio Breast Cancer Symposium. In this study, HER2-positive patients with a planned treatment with pertuzumab (loading dose $840 \mathrm{mg}$ followed by $420 \mathrm{mg}$ every 4 weeks) and trastuzumab (loading dose $8 \mathrm{mg} / \mathrm{kg}$, followed by $6 \mathrm{mg} / \mathrm{kg}$ every 4 weeks) were also included. The primary end point was pCR (defined as ypT0 ypN0 or N-positive); the secondary end points were pCR defined as ypT0/is ypN0 and ypT0 ypN0 0/+, toxicity, compliance, and pCR associated to secreted protein acidic and rich in cysteine (SPARC) expression. Some subgroup analyses were preplanned as per protocol. A total $23 \%$ of patients in both arms had a TNBC. The pCR rate (ypT0 


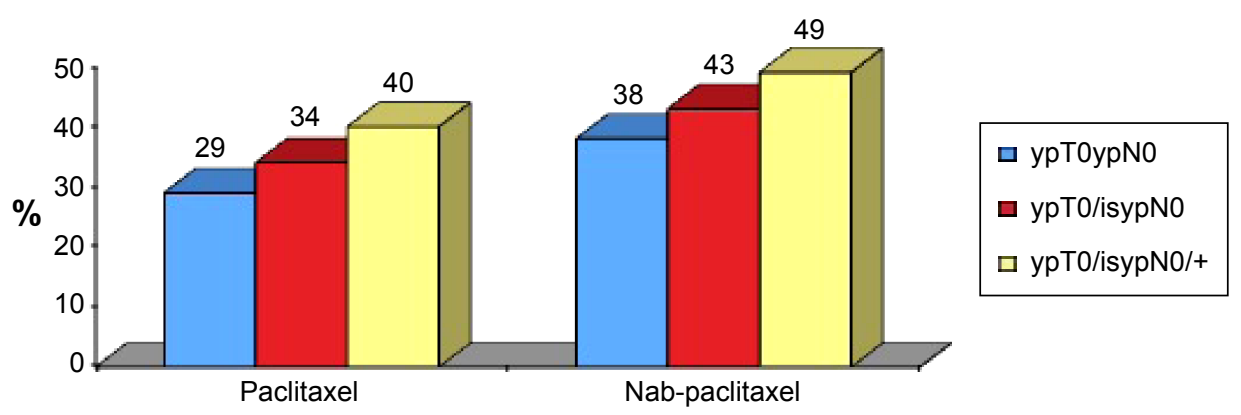

Figure 3 Pathological Response rate in patients treated with conventional paclitaxel or nab-paclitaxel. ${ }^{84}$

Notes: ypTOypNO: absence of tumor cells in Tumor and Nodes. ypTO/ispN0: absence of tumor cells in Tumor and Nodes, but in situ cancer cells in the tumor allowed. ypTO/ isypN0/+: Absence of tumor cells in Tumor and Nodes, but positive Nodes also allowed.

Abbreviation: $\mathrm{pCR}$, pathological complete response.

ypN0) was $29 \%$ in patients treated with paclitaxel and $38 \%$ in patients treated with nab-paclitaxel (OR 1.5, $P<0.01)$ (Figure 3).

The primary end point of pCR was reached with statistical significance. Actually, the odds ratio was 1.53 , indicating a $53 \%$ higher likelihood of achieving a pCR with albuminbound paclitaxel than with conventional paclitaxel.

The benefit observed with nab-paclitaxel was confirmed in all the subgroups of patients; in particular, it is noteworthy that in the TNBC population, the pCR was almost doubled (48.2\% vs $25.7 \%)(P<0.001)$. Globally, due to this very high increase of response in TNBC, nab-paclitaxel can be considered a valid therapeutic approach for the management of a disease characterized by a very poor prognosis.

\section{Safety profile}

Other important information from this study is the planned schedule, ie, weekly nab-paclitaxel $150 \mathrm{mg} / \mathrm{m}^{2}$, already used by Gradishar et al. ${ }^{69}$ After the enrolment of the first 400 patients, the protocol was amended, reducing the dose of weekly nab-paclitaxel to $125 \mathrm{mg} / \mathrm{m}^{2}$ for the further 800 patients. The safety profile was correctly reported (intent-totreat) for all the study population, showing the higher efficacy but also the higher toxicity of nab-paclitaxel in terms of grade $3 / 4$ sensitive neuropathy ( $10.2 \%$ vs $2.7 \%$ ). However, when considering ("per treatment given") only the patients treated with the dose of $125 \mathrm{mg} / \mathrm{m}^{2}$ of nab-paclitaxel $(800 / 1,200)$, the efficacy is the same but the toxicity is lower, without any difference in Grade 3 and Grade 4 toxicity (5.3\% vs 5.7\%) (Table 3).

An issue in the comparison between nab-paclitaxel and conventional paclitaxel in terms of neurotoxicity was also recently discussed at the ASCO 2015 meeting. In a Phase II trial (NCT0163710) of first-line treatment of metastatic HER2negative $\mathrm{BC}$ by Ciruelos et $\mathrm{al}^{86}$ weekly conventional paclitaxel $\left(80 \mathrm{mg} / \mathrm{m}^{2}\right)$ was compared with weekly nab-paclitaxel at the dose of $100 \mathrm{mgs} / \mathrm{sqm}$ days $1,8,15 ; 150 \mathrm{mgs} / \mathrm{sqm}$ days 1,8 , 15 or $150 \mathrm{mgs} / \mathrm{sqm}$ days 1, 15; any dose level any 28 days; neuropathy was the primary end point and neutropenia one of the secondary end points. The authors reported, as expected, an increased rate of Grade 3 neutropenia with weekly nabpaclitaxel at $150 \mathrm{mg}$, but no difference was reported between arms in terms of neurotoxicity or overall neutropenia.

Another trial - the randomized Phase II "ADAPT TN" trial - was reported at the ASCO 2015 meeting by Gluz et al.$^{87}$ Gemcitabine and carboplatin are interesting partners for taxane combinations, and the trial randomized 336 TNBC patients to 12 weeks of neoadjuvant nab-paclitaxel (125 mgs/sqm) and gemcitabine (1000 mgs/sqm) days 1 and $8 \mathrm{q} 3 \mathrm{w}$ or carboplatin $(\mathrm{AUC}=2)$. The end point was to identify early response markers for pCR (ypT0 ypN0) (drop of Ki-67 after 3 weeks from treatment start). The preplanned interim analysis with the first 130 patients was presented. pCR was reported in $25 \%$ of patients treated with nab-paclitaxel plus gemcitabine and in $49.2 \%$ of cases with nab-paclitaxel plus carboplatin $(P=0.006)$.

One more interesting paper on nab-paclitaxel was presented at the ASCO 2015 meeting, by Matsuda et al from the MD Anderson Cancer Center, ${ }^{88}$ based on the observations that EGFR overexpression is an independent poor prognostic factor in IBC and that in animal models an anti-EGFR treatment was able to inhibit IBC growth. In this single-arm Phase II study, 25 IBC patients were treated with the anti-EGFR

Table 3 Sensorial neuropathy (nab-paclitaxel at $\left.125 \mathrm{mg} / \mathrm{m}^{2}\right)^{84}$

\begin{tabular}{llll}
\hline & Paclitaxel \% & Nab-paclitaxel \% & P-value \\
\hline No neuropathy & 57.9 & 37.7 & 0.038 \\
Any G toxicity & 42.1 & 62.3 & ns \\
G3/4 & 5.3 & 5.7 & ns \\
\hline
\end{tabular}

Abbreviations: $\mathrm{G}$, grade; ns, not significant. 
monoclonal antibody panitumumab $(2.5 \mathrm{mg} / \mathrm{kg})$, nabpaclitaxel $\left(100 \mathrm{mg} / \mathrm{m}^{2}\right)$, and carboplatin (AUC =2) weekly, for four cycles, followed by four cycles of 5-Fluoruracile, Epirubicine at $100 \mathrm{mg} / \mathrm{sqm}$, Cyclophosphamide regimen, surgery, radiation, and endocrine adjuvant treatment in ERpositive cases. The overall pCR rate (primary end point) was $36 \%$ and was $60 \%$ in TNBC and $20 \%$ in ER-positive patients. The association of pCR with subtype showed just a trend to significance, essentially due to the small sample size. This excellent result was not "for free" because Grade 3 and 4 hematological events occurred in $72 \%$ and other Grade 3 events in a further $36 \%$ though the median age of patients was 57 years and patients were fit. The historical pCR rate in IBC is around $15 \%$ and the prognosis poor. These data have no precedent, and a randomized Phase III trial is now starting.

\section{Two clinical case reports Case report I}

A 52-year-old woman with primary TNBC metastasized to bones, locoregional and mediastinal nodes, and lung, was treated with nab-paclitaxel, gemcitabine, and bevacizumab. Pain improved within a few weeks, (complete withdrawal of analgesic therapy). After 7 months, a complete radiological response was observed and maintained for 2 years, with a dose reduction due to asthenia but without other adverse events. The patient maintained normal daily activities, including work; the disease progression occurred after 24 months. Subsequent treatments stabilized the disease; however, death occurred after another 2 years. This case is indicative of how a treatment with nab-paclitaxel, bevacizumab, and gemcitabine can be very effective with minimal toxicity in selected patients with metastatic TNBC. ${ }^{89}$

\section{Case report 2}

A 51-year-old women with TNBC, BRCA1-mutated, was treated with four cycles of a neoadjuvant carboplatin and etoposide regimen with a complete clinical/radiological response. A local progression after 19 months was treated with dosedense AC with growth factor support, followed by paclitaxel q3w for four cycles, with an optimal disease control. After a further 3 years, diffuse brain metastases were discovered, treated with whole-brain radiation, in a rapidly progressive disease (with massive liver and retroperitoneal nodes, and multiple, bilateral pulmonary involvement). The patient started a carboplatin $(\mathrm{AUC}=5)$ plus weekly nab-paclitaxel $100 \mathrm{mg} / \mathrm{m}^{2}$ regimen. Despite growth factor support, carboplatin was suspended after four cycles, and nab-paclitaxel monotherapy, at $90 \mathrm{mg} / \mathrm{m}^{2}$ weekly for 3 out 4 weeks, was continued. After 4 months, a partial response with clinical improvement was observed and maintained for another 4 months until asymptomatic cerebral disease progression, followed by a rapid deterioration in the patient's condition and exitus after 2 months.

This case is very interesting because it shows that in a patient heavily treated with carboplatin, etoposide, conventional paclitaxel, and anthracycline, third-line nab-paclitaxel, first combined with carboplatin for four cycles and then as monotherapy, was able to obtain a partial clinical/radiological response lasting for 8 months, with concomitant resolution of symptoms (pain, dyspnea, and severe asthenia) and virtual lack of toxicity. ${ }^{90}$

\section{New clinical trials of nab-paclitaxel in TNBC}

Some interesting trials with nab-paclitaxel in TNBC are currently ongoing.

\section{Tn Acity (ClinicalTrials.gov identifier NCT0I88I230 $)^{91}$}

- Randomized Phase II/III study of weekly nab-paclitaxel associated to gemcitabine or carboplatin vs gemcitabine plus carboplatin, in the first-line treatment of TNBC

- Phase II end points: efficacy (PFS) and safety of nabpaclitaxel $125 \mathrm{mg} / \mathrm{m}^{2}$ associated to gemcitabine or carboplatin vs their combination (randomized 1:1:1) $(n=240)$ - in order to identify the best nab-paclitaxelbased regimen to compare in the Phase III with the standard regimen, gemcitabine plus carboplatin (randomized $1: 1)(\mathrm{n}=550)$

- Phase III end point: PFS

- Phase III stratification factors: DFS $<$ or $>12$ months, pretreatment with taxanes in the adjuvant or neoadjuvant setting

- In both the study phases, treatment will continue until disease progression or unacceptable toxicity.

As of May 31, 2015, 176 patients were enrolled in the Phase II trial.

\section{ETNA (ClinicalTrials.gov identifier NCT0I8223 I4)}

- Randomized Phase III study on neoadjuvant therapy with weekly nab-paclitaxel

- 632 patients with early HER2-negative BC at high risk of relapse, Eastern Cooperative Oncology Group (ECOG) performance status $0-1$, to be randomized to weekly nab-paclitaxel $125 \mathrm{mg} / \mathrm{m}^{2}$ (three doses per cycle) for four cycles vs conventional weekly paclitaxel $90 \mathrm{mg} / \mathrm{m}^{2}$ (three doses per cycle) for four cycles, followed by four cycles 
of anthracycline-based regimens, surgery, and a 10-year follow up

- Primary end point: pCR (ypT0/ypTis, ypN0)

- Secondary end points:

○ pCR in endocrine receptor-positive vs triple-negative tumors

- ORR after four cycles of both taxanes and before surgery

- EFS (local, regional, and distant) and OS

- Safety and tolerability; clinical and molecular tests able to identify markers predictive of clinical benefit.

\section{Conclusion}

TNBC is characterized by the absence of ER-, PgR-, and HER2-negativity: for this reason the only therapeutic option is chemotherapy. Even if these tumors are chemosensitive, as showed by the high pCR obtained with neoadjuvant therapy, metastatic patients have a short PFS; thus the chemosensitivity does not translate in an improvement of PFS or OS, and the overall prognosis for these tumors is poor.

The studies performed with taxane-based chemotherapy demonstrated their efficacy in the treatment of TNBC in any setting (neoadjuvant, adjuvant, and metastatic): international and national guidelines recommend the taxanes as possible active first-line therapeutic options for TNBC.

Nab-paclitaxel, a nanoparticle of albumin-bound paclitaxel, allows achievement of higher intratumoral concentrations of active drug and is demonstrated to be more effective and less toxic that conventional taxanes in metastatic $\mathrm{BC}$; even in the case of aggressive and visceral disease and in neoadjuvant setting, the $\mathrm{pCR}$ is superior vs conventional taxanes.

\section{Author contributions}

Giorgio Mustacchi and Michelino De Laurentiis equally contributed to the conception, analysis, and interpretation of the literature, and drafting and revision of the paper, and both approved the final version. Both authors agree to be accountable for all aspects of the work.

\section{Disclosure}

This work was supported by an unconditional grant from Editree editors, Italy, and both authors received a fee. Giorgio Mustacchi receives honoraria from Roche, Celgene, and EISAI. Michelino De Laurentiis receives honoraria from Roche, Celgene, EISAI, Novartis, and AstraZeneca. The authors report no other conflicts of interest in this work.

\section{References}

1. Cardoso F, Harbeck N, Fallowfield L, Kyriakides S, Senkus E; ESMO Guidelines Working Group. Locally recurrent or metastatic breast cancer: ESMO Clinical Practice Guidelines for diagnosis, treatment and follow-up. Ann Oncol. 2012;23 Suppl 7:vii11-vii19.

2. AIOM-AIRTUM. I Numeri del Cancro in Italia. 2014 [The numbers of cancer in Italy. 2014]. AIOM-AIRTUM. Milan: Associazione Italiana di Oncologia Medica; 2014. Available from: http://www.aiom.it/ area+pubblica/area+medica/pubblicazioni/1,332,1. Accessed July 4, 2015. Italian.

3. de Rujters TC, Veeck, J, de Hoon JPJ, van Engeland M, Tjan-Heijnen VC Characteristics of triple-negative breast cancer. J Cancer Res Clin Oncol. 2011;137:183-192.

4. Chacón RD, Costanzo MV. Triple-negative breast cancer. Breast Cancer Res. 2010;12 Suppl 2:S3.

5. Hudis CA, Gianni L. Triple-negative breast cancer: an unmet medical need. Oncologist. 2011;16 Suppl 1:S1-S11.

6. Rapoport BL, Nayler S, Demetriou GS, Moodley SD, Benn CA. Triplenegative breast cancer pathologic diagnosis and current chemotherapy treatment options. Oncol Hematol Rev. 2014;10(1):25-32.

7. Sørlie T, Perou CM, Tibshirani R, et al. Gene expression patterns of breast carcinomas distinguish tumor subclasses with clinical implications. Proc Natl Acad Sci U S A. 2001;98(19):10869-10874.

8. van't Veer LJ, Dai H, van de Vijver MJ, et al. Gene expression profiling predicts clinical outcome of breast cancer. Nature. 2002;415(687):530-536

9. Hortobagyi GN, Hayes D, Pusztai L. Integrating newer science into breast cancer prognosis and treatment: Molecular predictors and profiles. In: Johnson DH, editor. American Society of Clinical Oncology 2002 Annual Meeting Summaries, Orlando, FL, May 18-21, 2002. Alexandria, VA: American Society of Clinical Oncology; 2002: 91-202.

10. Ayers M, Symmans WF, Stec J, et al. Gene expression profiles predict complete pathologic response to neoadjuvant paclitaxel and fluorouracil, doxorubicin, and cyclophosphamide chemotherapy in breast cancer. J Clin Oncol. 2004;22(12):2284-2293.

11. Dent R, Trudeau M, Pritchard KI, etal. Triple-negative breast cancer: clinical features and patterns of recurrence. Clin Cancer Res. 2007;13(15 Pt 1): 4429-4434.

12. Lehmann BD, Bauer JA, Chen X, et al. Identification of human triplenegative breast cancer subtypes and preclinical models for selection of targeted therapies. J Clin Invest. 2011;121(7):2750-2767.

13. Lehmann BD, Pietenpol JA, Tan AR. Triple-negative breast cancer: molecular subtypes and new targets for therapy. Am Soc Clin Oncol Educ Book. 2015;35:e31-e39.

14. Tobin NP, Harrell JC, Egyhazi Brage S, et al. Molecular subtype of breast cancer metastases significantly influences patient post-relapse survival. Ann Oncol. 2014;25(Suppl 1):i5-i7. Abstract.

15. Dent RA, Mainwaring PN, Tan TJY, et al. Survival in triple-negative breast cancer (TNBC): Evidence from the SEER database 2010-2011. J Clin Oncol. 2015;33(Suppl 15):e12075. Abstract.

16. National Comprehensive Cancer Network (NCCN). Clinical Practice Guidelines in Oncology. Breast Cancer. version 2.2014. Washington, PA: National Comprehensive Cancer Network; 2014.

17. Associazione Italiana di Oncologia Medica (AIOM). Linee Guida: Neoplasie della Mammella [Guidelines: Neoplasms of the Breast] Milan: Associazione Italiana di Oncologia Medica; 2013. Italian.

18. Cortazar P, Zhang L, Untch M, et al. Pathological complete response and long-term clinical benefit in breast cancer: the CTNeoBC pooled analysis. Lancet. 2014;384(9938):164-172.

19. Cortazar P, Geyer CE Jr, Gianni L, Cameron D, von Minckwitz G. Pathological complete response in breast cancer - Authors' reply. Lancet. 2015;385:114-115.

20. von Minckwitz G, Untch M, Nüesch E, et al. Impact of treatment characteristics on response of different breast cancer phenotypes: pooled analysis of the German neo-adjuvant chemotherapy trials. Breast Cancer Res Treat. 2011;125(1):145-156. 
21. von Minckwitz G, Untch M, Blohmer JU, et al. Definition and impact of pathologic complete response on prognosis after neoadjuvant chemotherapy in various intrinsic breast cancer subtypes. J Clin Oncol. 2012; 30(15):1796-1804.

22. Rouzier R, Perou CM, Symmans WF, et al. Breast cancer molecular subtypes respond differently to preoperative chemotherapy. Clin Cancer Res. 2005;11(16):5678-5685.

23. Liedtke C, Mazouni C, Hess KR, et al. Response to neoadjuvant therapy and long-term survival in patients with triple-negative breast cancer. J Clin Oncol. 2008;26(8):1275-1281.

24. Guarneri V, Broglio K, Kau SW, et al. Prognostic value of pathologic complete response after primary chemotherapy in relation to hormone receptor status and other factors. J Clin Oncol. 2006;24(7):1037-1044.

25. Wang S, Yang H, Tong F, et al. Response to neoadjuvant therapy and disease free survival in patients with triple-negative breast cancer. Gan To Kagaku Ryoho. 2009;36(2):255-258.

26. Torrisi R, Balduzzi A, Ghisini R, et al. Tailored preoperative treatment of locally advanced triple negative (hormone receptor negative and HER2 negative) breast cancer with epirubicin, cisplatin, and infusional fluorouracil followed by weekly paclitaxel. Cancer Chemother Pharmacol. 2008;62(4):667-672.

27. von Minckwitz G, Raab G, Caputo A, et al. Doxorubicin with cyclophosphamide followed by docetaxel every 21 days compared with doxorubicin and docetaxel every 14 days as preoperative treatment in operable breast cancer: the GEPARDUO study of the German Breast Group. J Clin Oncol. 2005;23(12):2676-2685.

28. Darb-Esfahani S, Loibl S, Müller BM, et al. Identification of biologybased breast cancer types with distinct predictive and prognostic features: role of steroid hormone and HER2 receptor expression in patients treated with neoadjuvant anthracycline/taxane-based chemotherapy. Breast Cancer Res. 2009;11(5):R69.

29. Esserman LJ, Perou C, Cheang M, et al; I-SPY Investigators. Breast cancer molecular profiles and tumor response of neoadjuvant doxorubicin and paclitaxel: The I-SPY TRIAL (CALGB 150007/150012, ACRIN 6657). J Clin Oncol. 2009;27(Suppl 15S):LBA515. Abstract.

30. Wu J, Li S, Jia W, Su F. Response and prognosis of taxanes and anthracyclines neoadjuvant chemotherapy in patients with triple-negative breast cancer. J Cancer Res Clin Oncol. 2011;137(10):1505-1510.

31. Sakuma K, Kurosumi M, Oba H, et al. Pathological tumor response to neoadjuvant chemotherapy using anthracycline and taxanes in patients with triple-negative breast cancer. Exp Ther Med. 2011;2(2):257-264.

32. André F, Zielinski CC. Optimal strategies for the treatment of metastatic triple-negative breast cancer with currently approved agents. Ann Oncol. 2012;23 Suppl 6:vi46-vi51.

33. Andre F, Deluche E, Bonnefoi H. Bevacizumab: the phoenix of breast oncology? Lancet Oncol. 2015;16(6):600-601.

34. Kim HR, Jung KH, Im SA, et al. Multicentre phase II trial of bevacizumab combined with docetaxel-carboplatin for the neoadjuvant treatment of triple-negative breast cancer (KCSG BR-0905). Ann Oncol. 2013;24(6):1485-1490.

35. von Minckwitz G, Eidtmann H, Rezai M, et al; German Breast Group; Arbeitsgemeinschaft Gynäkologische Onkologie-Breast Study Groups. Neoadjuvant chemotherapy and bevacizumab for HER2-negative breast cancer. N Engl J Med. 2012;366(4):299-309.

36. Bear HD, Tang G, Rastogi P, et al. Bevacizumab added to neoadjuvant chemotherapy for breast cancer. $N$ Engl J Med. 2012;366(4): 310-320.

37. von Minckwitz G, Schneeweiss A, Loibl S, et al. Neoadjuvant carboplatin in patients with triple-negative and HER2-positive early breast cancer (GeparSixto; GBG 66): a randomised phase 2 trial. Lancet Oncol. 2014;15(7):747-756.

38. Von Minckwitz G, Timms K, Untch M, et al. Prediction of pathological complete response (pCR) by Homologous Recombination Deficiency (HRD) after carboplatin-containing neoadjuvant chemotherapy in patients with TNBC: Results from GeparSixto. J Clin Oncol. 2015;33(Suppl 15):1004. Abstract.
39. Sikov WM, Berry DA, Perou CM, et al. Impact of the addition of carboplatin and/or bevacizumab to neoadjuvant once-per-week paclitaxel followed by dose-dense doxorubicin and cyclophosphamide on pathologic complete response rates in stage II to III triple-negative breast cancer: CALGB 40603 (Alliance). J Clin Oncol. 2015;33(1): 13-21.

40. Golshan M, Cirrincione CT, Carey LA, et al. Impact of neoadjuvant therapy on breast conservation rates in triple-negative and HER2positive breast cancer: Combined results of CALGB 40603 and 40601 (Alliance). J Clin Oncol. 2015;33(Suppl 15):1007. Abstract.

41. Earl HM, Hiller L, Dunn JA, et al; ARTemis Investigators. Efficacy of neoadjuvant bevacizumab added to docetaxel followed by fluorouracil, epirubicin, and cyclophosphamide, for women with HER2-negative early breast cancer (ARTemis): an open-label, randomised, phase 3 trial. Lancet Oncol. 2015;16(6):656-666.

42. Hayes DF, Thor AD, Dressler LG, et al; Cancer and Leukemia Group B (CALGB) Investigators. HER2 and response to paclitaxel in nodepositive breast cancer. $N$ Engl J Med. 2007;357(15):1496-1506.

43. Sparano JA, Zhao F, Martino S, et al. Long-term follow-up of the E1199 Phase III trial evaluating the role of taxane and schedule in operable breast cancer. J Clin Oncol. Epub 2015 Jun 15.

44. Hugh J, Hanson J, Cheang MC, et al. Breast cancer subtypes and response to docetaxel in node-positive breast cancer: use of an immunohistochemical definition in the BCIRG 001 trial. J Clin Oncol. 2009;27(8): 1168-1176.

45. Loesch D, Greco F, O'Shaughnessy J, et al. A randomized, multicenter, phase III trial comparing doxorubicin + cyclophosphamide followed by paclitaxel or doxorubicin + paclitaxel followed by weekly paclitaxel as adjuvant therapy for high-risk breast cancer. J Clin Oncol. 2007;25(Suppl 18):517. Abstract.

46. Jacquin JP, Jones S, Magné N, et al. Docetaxel-containing adjuvant chemotherapy in patients with early stage breast cancer. Consistency of effect independent of nodal and biomarker status: a meta-analysis of 14 randomized clinical trials. Breast Cancer Res Treat. 2012;134(3): 903-913.

47. Yardley DA, Bosserman LD, Keaton MR, et al. TITAN: Phase III study of doxorubicin/cyclophosphamide (AC) followed by ixabepilone (Ixa) or paclitaxel (Pac) in early-stage, triple-negative breast cancer (TNBC). J Clin Oncol. 2015;33(15 Suppl):1000. Abstract.

48. Cameron D, Brown J, Dent R, et al. Adjuvant bevacizumab-containing therapy in triple-negative breast cancer (BEATRICE): primary results of a randomised, phase 3 trial. Lancet Oncol. 2013;14(10):933-942.

49. Ghersi D, Willson ML, Chan MM, Simes J, Donoghue E, Wilcken N. Taxane-containing regimens for metastatic breast cancer. Cochrane Database Syst Rev. 2015;6:CD003366.

50. Isakoff SJ. Triple-negative breast cancer: role of specific chemotherapy agents. Cancer J. 2010;16(1):53-61.

51. Kassam F, Enright K, Dent R, et al. Survival outcomes for patients with metastatic triple-negative breast cancer: implications for clinical practice and trial design. Clin Breast Cancer. 2009;9(1):29-33.

52. O'Shaughnessy J, Romieu G, Diéras V et al. Meta-analysis of patients with triple negative breast cancer (TNBC) from three randomized trials of first-line bevacizumab (BV) and chemotherapy treatment for metastatic breast cancer (MBC). In: Programs and abstracts of the 33rd Annual CTRC-AACR San Antonio Breast Cancer Symposium; December 8-12, 2010; San Antonio, TX. Abstract P6-12-03.

53. Brufsky A, Valero V, Tiangco B, etal. Second-line bevacizumab-containing therapy in patients with triple-negative breast cancer: subgroup analysis of the RIBBON-2 trial. Breast Cancer Res Treat. 2012;133(3): 1067-1075

54. Gligorov J, Doval D, Bines J, et al. Maintenance capecitabine and bevacizumab versus bevacizumab alone after initial first-line bevacizumab and docetaxel for patients with HER2-negative metastatic breast cancer (IMELDA): a randomised, open-label, phase 3 trial. Lancet Oncol. 2014;15(12):1351-1360. 
55. Gennari A, Stockler M, Puntoni M, et al. Duration of chemotherapy for metastatic breast cancer: a systematic review and meta-analysis of randomized clinical trials. J Clin Oncol. 2011;29(16):2144-2149.

56. Fan Y, Xu BH, Yuan P, et al. Docetaxel-cisplatin might be superior to docetaxel-capecitabine in the first-line treatment of metastatic triplenegative breast cancer. Ann Oncol. 2013;24(5):1219-1225.

57. Tutt A, Ellis P, Kilburn L, et al. TNT: A randomized phase III trial of carboplatin (C) compared with docetaxel (D) for patients with metastatic or recurrent locally advanced triple negative or BRCA1/2 breast cancer (CRUK/07/012). In: Programs and abstracts of the 37th Annual CTRCAACR San Antonio Breast Cancer Symposium; December 9-13, 2014; San Antonio, TX. Abstract S3-01.

58. Aogi K, Yoshida M, Sagara Y, et al. The efficacy and safety of gemcitabine plus paclitaxel combination first-line therapy for Japanese patients with metastatic breast cancer including triple-negative phenotype. Cancer Chemother Pharmacol. 2011;67(5):1007-1015.

59. Dent RA, Lindeman GJ, Clemons M, et al. Phase I trial of the oral PARP inhibitor olaparib in combination with paclitaxel for first- or second-line treatment of patients with metastatic triple-negative breast cancer. Breast Cancer Res. 2013;15(5):R88.

60. Parker JS, Peterson AC, Tudor IC, Hoffman J, Uppal H. A novel biomarker to predict sensitivity to enzalutamide (ENZA) in TNBC. $J$ Clin Oncol. 2015;33(15 Suppl):1083. Abstract.

61. Petrelli F, Borgonovo K, Barni S. Targeted delivery for breast cancer therapy: the history of nanoparticle-albumin-bound paclitaxel. Expert Opin Pharmacother. 2010;11(8):1413-1432.

62. Piccart M. Nab ${ }^{\mathrm{TM}}$-paclitaxel: a targeted chemotherapy to improve outcomes in metastatic breast cancer. APJOH. 2009;1(1):5-12.

63. Desai N, Trieu V, Yao Z, et al. Increased antitumor activity, intratumor paclitaxel concentrations, and endothelial cell transport of cremophorfree, albumin-bound paclitaxel, ABI-007, compared with cremophorbased paclitaxel. Clin Cancer Res. 2006;12(4):1317-1324.

64. Scheff RJ. Breast cancer and the new taxanes: focus on nab-paclitaxel. Community Oncol. 2008;5(7 Supp1 8):S7-S13.

65. Yardley DA. Nab-Paclitaxel mechanisms of action and delivery. $J$ Control Release. 2013;170(3):365-372.

66. Gradishar WJ, Tjulandin S, Davidson N, et al. Phase III trial of nanoparticle albumin-bound paclitaxel compared with polyethylated castor oil-based paclitaxel in women with breast cancer. J Clin Oncol. 2005 23(31):7794-7803.

67. Gonzalez-Angulo AM, Hortobagyi GN. Optimal schedule of paclitaxel: weekly is better. J Clin Oncol. 2008;26(10):1585-1587.

68. Green MC, Buzdar AU, Smith T, et al. Weekly paclitaxel improves pathologic complete remission in operable breast cancer when compared with paclitaxel once every 3 weeks. J Clin Oncol. 2005;23(25):5983-5992.

69. Seidman AD, Berry D, Cirrincione C, et al: Randomized phase III trial of weekly compared with every-3-weeks paclitaxel for metastatic breast cancer, with trastuzumab for all HER-2 overexpressors and random assignment to trastuzumab or not in HER-2 nonoverexpressors: final results of Cancer and Leukemia Group B protocol 9840. J Clin Oncol. 2008;26(10):1642-1649.

70. Gradishar WJ, Krasnojon D, Cheporov S, et al. Significantly longer progression-free survival with nab-paclitaxel compared with docetaxel as first-line therapy for metastatic breast cancer. J Clin Oncol. 2009;27(22): 3611-3619.

71. Gradishar WJ, Krasnojon D, Cheporov S, et al. Phase II trial of nab-paclitaxel compared with docetaxel as first-line chemotherapy in patients with metastatic breast cancer: final analysis of overall survival. Clin Breast Cancer. 2012;12(5):313-321.

72. O’Shaughnessy J, Gradishar WJ, Bhar P, Iglesias J. Nab-paclitaxel for first-line treatment of patients with metastatic breast cancer and poor prognostic factors: a retrospective analysis. Breast Cancer Res Treat. 2013;138(3):829-837.

73. Blum JL, Savin MA, Edelman G, et al. Phase II study of weekly albuminbound paclitaxel for patients with metastatic breast cancer heavily pretreated with taxanes. Clin Breast Cancer. 2007;7(11):850-856.
74. Palumbo R, Sottotetti F, Trifirò G, et al. Nanoparticle albumin-bound paclitaxel (nab-paclitaxel) as second-line chemotherapy in HER2negative, taxane-pretreated metastatic breast cancer patients: prospective evaluation of activity, safety, and quality of life. Drug Des Devel Ther. 2015;9:2189-2199.

75. Schwartzberg LS, Arena FP, Mintzer DM, Epperson AL, Walker MS. Phase II multicenter trial of albumin-bound paclitaxel and capecitabine in first-line treatment of patients with metastatic breast cancer. Clin Breast Cancer. 2012;12(2):87-93.

76. Roy V, LaPlant BR, Gross GG, Bane CL, Palmieri FM; North Central Cancer Treatment Group. Phase II trial of weekly nab (nanoparticle albumin-bound)-paclitaxel (nab-paclitaxel) (Abraxane) in combination with gemcitabine in patients with metastatic breast cancer (N0531). Ann Oncol. 2009;20(3):449-453.

77. Lobo C, Lopes G, Baez O, et al. Final results of a phase II study of nab-paclitaxel, bevacizumab, and gemcitabine as first-line therapy for patients with HER2-negative metastatic breast cancer. Breast Cancer Res Treat. 2010;123(2):427-435.

78. Hamilton E, Kimmick G, Hopkins J, et al. Nab-paclitaxel/bevacizumab/ carboplatin chemotherapy in first-line triple negative metastatic breast cancer. Clin Breast Cancer. 2013;13(6):416-420.

79. Rugo HS, Barry WT, Moreno-Aspitia A, et al. Randomized phase III trial of paclitaxel once per week compared with nanoparticle albuminbound nab-paclitaxel once per week or ixabepilone with bevacizumab as first-line chemotherapy for locally recurrent or metastatic breast cancer: CALGB 40502/NCCTG N063H (Alliance). J Clin Oncol. Epub 2015 June 8 .

80. Tonissi F, Lattanzio L, Merlano MC, Infante L, Lo Nigro C, Garrone O. The effect of paclitaxel and nab-paclitaxel in combination with antiangiogenic therapy in breast cancer cell lines. Invest New Drugs. Epub 2015 May 7.

81. Low JA, Berman AW, Steinberg SM, Danforth DN, Lippman ME, Swain SM. Long-term follow-up for locally advanced and inflammatory breast cancer patients treated with multimodality therapy. J Clin Oncol. 2004;22(20):4067-4074.

82. Nahleh ZA, Barlow WE, Hayes DF, et al. S0800: Nab-paclitaxel, doxorubicin, cyclophosphamide, and pegfilgrastim with or without bevacizumab in treating women with inflammatory or locally advanced breast cancer (NCI CDR0000636131). In: Programs and abstracts of the 37th Annual CTRC-AACR San Antonio Breast Cancer Symposium; December 9-13, 2014; San Antonio, TX. Abstract P3-11-16.

83. Snider JN, Sachdev JC, Allen JW, et al. Pathologic complete response (pCR) with weekly nanoparticle albumin bound (Nab-P) plus carboplatin (C) followed by doxorubicin plus cyclophosphamide (AC) with concurrent bevacizumab (B) for triple-negative breast cancer (TNBC). J Clin Oncol. 2013;31(15 Supp1):1068. Abstract.

84. Huang L, Chen S, Yao L, Liu G, Wu J, Shao Z. Phase II trial of weekly nab-paclitaxel and carboplatin treatment with or without trastuzumab as nonanthracycline neoadjuvant chemotherapy for locally advanced breast cancer. Int J Nanomedicine. 2015;10:1969-1975.

85. Untch M, Jackisch C, Schneeweiß A, et al. A randomized phase III trial comparing neoadjuvant chemotherapy with weekly nanoparticlebased paclitaxel with solvent-based paclitaxel followed by anthracyline/ cyclophosphamide for patients with early breast cancer (GeparSepto); GBG 69. In: Program and abstracts of the 35th Annual CTRC-AACR San Antonio Breast Cancer Symposium; December 4-8, 2012; San Antonio, TX. Abstract OT3-3 PD2-D6.

86. Ciruelos E, Martinez N, Cantos B, et al. Phase II randomized study of nab-paclitaxel versus conventional paclitaxel as first-line therapy of metastatic HER2-negative breast cancer for neurotoxicity characterization: An Oncosur Study Group study. J Clin Oncol. 2015; 33(15 Supp1):1029. Abstract.

87. Gluz O, Nitz U, Christgen M, et al. Efficacy of 12 weeks neoadjuvant nab-paclitaxel combined with carboplatinum vs gemcitabine in triplenegative breast cancer: WSG-ADAPT TN randomized phase II trial. J Clin Oncol. 2015;33(15 Suppl):1032. Abstract. 
88. Matsuda N, Alvarez RH, Krishnamurthy S, et al. Phase II study of panitumumab, nab-paclitaxel, and carboplatin followed by FEC neoadjuvant chemotherapy for patients with primary HER-2 negative inflammatory breast cancer. J Clin Oncol. 2015;33(15 Suppl):1065. Abstract.

89. Montero A, Glück S. Long-term complete remission with nab-paclitaxel, bevacizumab, and gemcitabine combination therapy in a patient with triple-negative metastatic breast cancer. Case Rep Oncol. 2012;5(3): 687-692.
90. Shakir AR. Strong and sustained response to treatment with carboplatin plus nab-paclitaxel in a patient with metastatic, triple-negative, BRCA1positive breast cancer. Case Rep Oncol. 2014;7(1):252-259.

91. Yardley DA, Cortes J, Coleman RE, et al. Weekly nab-paclitaxel (nab-P) plus gemcitabine (gem) or carboplatin (carbo) vs gem/carbo as first-line treatment for metastatic triple-negative breast cancer (mTNBC) in a phase 2/3 trial (tnAcity). J Clin Oncol. 2015;33(15 Suppl):TPS1106. Abstract.

\section{Publish your work in this journal}

Drug Design, Development and Therapy is an international, peerreviewed open-access journal that spans the spectrum of drug design and development through to clinical applications. Clinical outcomes, patient safety, and programs for the development and effective, safe, and sustained use of medicines are a feature of the journal, which has also been accepted for indexing on PubMed Central. The manuscript management system is completely online and includes a very quick and fair peer-review system, which is all easy to use. Visit http://www.dovepress.com/testimonials.php to read real quotes from published authors.

Submit your manuscript here: http://www.dovepress.com/drug-design-development-and-therapy-journal 